\title{
KORUPSI DARI PERSPEKTIF ALQURAN DAN KEARIFAN LOKAL: PENYEBAB, DAMPAK, DAN PENCEGAHANNYA
}

\author{
Muhammad Yusuf \\ Sekolah Tinggi Agama Islam (STAI) Al-Furqan, Makassar, Indonesia \\ E-mail: dr.muhammad.yusuf.m.pdi@gmail.com \\ Ismail Suardi Wekke \\ Sekolah Tinggi Agama Islam Negeri (STAIN) Sorong, Papua Barat, Indonesia \\ E-mail: iswekke@gmail.com \\ Presented in \\ Internasional Conference on Islam and Local wisdom (ICLAW) \\ Kendari, Indonesia, 25-26 April, 2017
}

\begin{abstract}
Abstrak: Korupsi merupakan suatu kejahatan yang merugikan dan membahayakan secara individu dan secara kolektif. Oleh karena itu, kejahatan korupsi harus dicegah dan diatasi. Untuk mencegah korupsi, maka terlebih dahulu dicari faktor penyebabnya, kemudian dirumuskan pencegahannya. Artikel ini bertujuan mengelaborasi tuntunan Alquran dan kearifan lokal Bugis mengenai faktor penyebab korupsi dan bagaimana petunjuk Alquran dalam menawarkan pencegahan terhadap kejahatan korupsi tersebut. Untuk memahami petunjuk Alquran mengatasi dan mencegah korupsi, artiekl ini melakukan analisisnya dengan menggunakan pendekatan linguistik Arab. Selain itu, mengintegrasikan petunjuk Alquran dengan nilai-nilai kearifan lokal yang bersumber dari budaya Bugis yang relevan dengan pencegahan korupsi. Artikel ini menunjukkan, Alquran memulai pencegahan korupsi pada dua cara; pertama, dilakukan melalui reformasi secara total pada struktural. Kedua, dimulai dari 'sisi dalam' pada manusia berdasarkan pada konsep nafsun dalam Alquran. Adapun secara kultural, pencegahan korupsi harus senantiasa merujuk pada prinsip lempu', amaccang, agettengeng, asitinajang, reso, and siri'. Nilai-nilai ini harus diperkuat dan diperdalam (dihayati) dalam kehidupan dalam kehidupan. Singkatnya, nilai-nilai kearifan lokal sangat urgen untuk diperkenalkan kembali dan diajarkan, kususnya kepada generasi muda sebelum benar-benar menjadi pemimpin.
\end{abstract}

Kata Kaunci: Korupsi, Alquran, kearifan lokal, nafsun, Pencegahan

\section{CORRUPTION IN THE QURANIC AND LOCAL WISDOM PERSPECTIVE: CAUSES DAN PREVENTIONS}

Abstract: Corruption is a crime which harms and endangers individually and collectively. Therefore, the corruption offenses must be prevented and treated. To prevent it, the causative factors must be figured out, then to formulate prevention of it. This article aims to elaborate guidance of the Quran and local wisdom of Bugis about causative factors of it, and how the guidance of the Quran to prevent. To understand guidance of the Quran in treating and preventing it, this article analyzes with Arabic linguistics approach. The other is to integrate Quranic guidances and values of local wisdom of Bugis culture that's relevant for preventing corruption. This article shows, the Quran begins to prevent corruption offenses in two ways; firstly, to reform the birocration totally based on plural word "anfus". The other, to start from inner hidden based on concept of "nafsun" and "anfus". And based on Bugis culture, 
prevention refers to principles of lempu', amaccang, agettengeng, asitinajang, reso, and siri'. These values and others have to be strengthened and deepened in people's life. In short, the local wisdom is very urgent to introduce and to teach to people, especially for young generation before becoming real leaders.

Keywords: Corruption, the Quran, local wisdom, nafsun, causative factor, prevent.

\section{INTRODUCTION}

Analisis terhadap permasalahan korupsi merupakan sebuah ikhtiar yang urgen dan relevan saat ini. Permasalahan korupsi yang dialami oleh bangsa-bangsa di dunia khususnya Indonesia merupakan fakta yang selalu menghiasi pemberitaan media. Negara yang berdasarkan Ketuhan yang Maha Esa sejatinya penyelenggaran kehidupan bernegara dan bermasyarakat semestinya menjadikan agama sebagai landasan utama terhadap nilai-nilai keadilan sosial. Faktanya adanya sejumlah kasus korupsi menunjukkan kesenjangan antara nilai-nilai agama dan prilaku penganutnya. Para koruptor umumnya mereka penganut agamaagama yang ada. Hal ini tentu memperkuat asumsi bahwa agama mengalami disfungsi dalam penyelenggaraan negara.

Demikian pula Negara Indonesia yang berdiri di atas pilar Bhineka Tunggal Ika ini juga mengalami fakta yang berbanding terbalik. Kebhinekaan adalah keragaman dan keragaman adalah kekayaan akan sumber nilai-nilai luhur. Nilai-nilai luhur itu berasal dari beragam budaya dan agama yang menunjukkan Indonesia yang sesungguhnya. Keadaan ini meniscayakan masyarakat Indonesia harus menghormati local value [1] sebab Indonesia memiliki karakter keragaman yang khas, memiliki nilai-nilai kearifan lokal yang mencerminkan Islam Indonesia yang sesungguhnya. Ditengah-tengah keragaman budaya, masyarakt Bugis memiliki posisi yang penting, sebab orang-orang Bugis banyak memegang peran penting dalam menata Indonesia. Dengan menghayati dan mengamalkan nilai-nilai agama dan kearifan budayanya, semestinya Indonesia terbebas dari prilaku korupsi. Termasuk perlunya perjumpaan antara budaya dengan keberagamaan [2].

Ketika perilaku aparatur tidak bisa lagi dikendalikan melalui pengawasan pimpinan, maka pengawasan dengan pendekatan agama (PPA) dijadikan sebagai alternatif sebagai model pengawasan dini yang pendekatannya lebih menekankan pada pembedayaan nilai-nilai agama. Pendekatan ini dikembangkan untuk mendorong terbentuknya karakter dan jati diri aparatur negara melalui pemahaman terhadap nilai-nilai agama, agar mampu menjalankan fungsi kontrol diri (self control) atau pengawasan diri dalam rangka membangun pemerintahan dan budaya kerja yang baik dan bersih [3]. Begitu juga dalam proses 
pendidikan [4]. Konsep percaya pada akhirat mengajarkan bahwa "cukup dirimu sendiri yang menghisab dirimu sendiri" sebagaimana petunjuk surah al-Isra' ayat 14 .

Tindak kejahatan korupsi ini bertentangan dengan nilai Alquran yang mengajarkan kejujuran dan keadilan. Demikian pula korupsi bertentangan dengan prinsip budaya lempu', amaccang, agettengeng, asitinajang, reso, and siri'. Hal ini tentu menimbulkan sejumlah pertanyaan mendasar; 1) Faktor apa yang mendorong terjadinya kejahatan korupsi? 2) Bagaimana dampak buruk yang ditimbulkan akibat korupsi? Dan, 3) bagaimana mengatasi dan mencegah korupsi tersebut? Tiga pertanyaan ini tentu membutuhkan pengkajian akademik dan ilmiah untuk mengelaborasinya.

\section{METHOD}

Kajian terhadap konsep qurani tentang korupsi didekati dengan pelacakan istilah secara implisit. Pendekatan yang digunakan adalah pendekatan linguistik [5], interrelationship [6] yang lebih dikenal dengan istilah munasabah, dan kontekstual [7] (konteks historis dan konteks realitas) yakni mempertemukan antara konteks turunnya ayat dan relaitas sosial yang terus mengalami dinamika. Kajian terhadap konsep Qurani mengenai korupsi yang mencakup sebab, akibat, dan pencegahannya. Analisis konsep qurani melalui penggalian konsep "nafsun-tunggal" atau "anfus - jamak". Sebab, Alquran mengisyaratkan bahwa penyebab korupsi antara lain adalah karena pelakunya memperturutkan hawa nafsu dan syahwat duinawi. Karena dorongan materialisme yang kuat, sementara prinsip lempu', amaccang, agettengeng, asitinajang, reso, and siri' dalam kebudayaan Bugis semakin melemah maka nilai-nilai itu dikesamping. Dampak yang buruk yang ditimbulkan oleh korupsi mencakup berbagai aspek kehidupan sosial, ekonomi, politik, keadilan ikut tergerus. Manusia sebagai makhluk sosial yang religius dan berbudaya seolah tergerus oleh pengaruh materialisme. Hal ini membutuhkan analisis yang relevan. Tugas yang urgen direalisasikan adalah bagaimana memberdayakan nilai-nilai Alquran bagi umat Islam dan nilai budaya Bugis mewarnai penyelenggaraan negara dan masyarakat.

\section{KAJIAN TEORI}

Ada beberapa pengertian tentang korupsi dari para ahli, diantaranya J.W. Schoorl, korupsi adalah penggunaan kekuasaan negara untuk memperoleh penghasilan, keuntungan, atau prestise perorangan atau untuk memberi keuntungan bagi sekelompok orang atau kelas sosial dengan cara yang bertentangan dengan undang-undang atau dengan norma akhlak yang 
tinggi" [8] Yang dimaksud korupsi adalah segala usaha mencari keuntungan untuk diri sendiri danga jalan tidak wajar dan merugikan sesama manusia, yang selalu bertemu dalam masyarakat.Sehingga orang beroleh kekayaan dengan penghisapan dan penipuan kepada sesamanya manusia. [9] Korupsi sebagai penyelewengan atau penggelapan uang negara atau perusahaan dan sebagainya untuk kepentingan pribadi maupun orang lain. [10]

Dari pengertian di atas menunjukkan bahwa tindakan korupsi adalah suatu penyimpangan yang terjadi baik itu di suatu lembaga pemerintahan maupun di masyarakat tertentu. Tindakan korupsi juga dapat terjadi di sekelompok orang atau kelas sosial selain di lembaga pemerintahan yang serakah atau tamak. Hanya saja, lembaga pendidikan akan menjadi bagian dalam rekonstruksi kemasyarakatan [11]

\section{HASIL DAN PEMBAHASAN}

\section{Corruption in The Quran Perspective}

Alquran memberi petunjuk melarang memakan (mengambil, merampas) hartta orang lain dengan cara yang batil. "Dan janganlah sebahagian kamu memakan harta sebahagian yang lain di antara kamu dengan jalan yang bathil dan (janganlah) kamu membawa (urusan) harta itu kepada hakim, supaya kamu dapat memakan sebahagian daripada harta benda orang lain itu dengan (jalan berbuat) dosa, Padahal kamu mengetahui. (Q.S. al-Baqarah [2]:188). Cara yang batil (ilegal) diantaranya adlah korupsi. Al-Bathil: asal katanya adalah buthlan, artinya yaitu curang atau merugikan. Mengambil harta dengan cara bathil berarti mengambil dengan cara tanpa imbalan sesuatu yang hakiki. Sedangkan al-Itsm berarti perbuatan dosa. Yang dimaksud disini adalah kesaksian palsu atau sumpah semu dan yang sejenisnya [12].

Allah Swt. yang memberikan rizki terhadap siapa saja, tidak sepatutnya memperluas kebatilan dan mempersempit kebenaran (haq), seperti halnya sirqoh (mencuri) dan ghasab (merampas) karena perbuatan tersebut cenderung merugikan orang lain, perbuatan tersebut sama halnya dengan korupsi yang cenderung dari perwujudan tidak bermoral. [13]

Term akl' pada Q.S. al-Baqarah /2:188 tersebut bermakna mengambil sesuatu dengan jalan yang dilarang oleh syariat agama yang dapat diartikan dengan korupsi, karena hal itu merupakan suatu perbuatan yang bathil. Mengambil harta dengan cara yang bathil memiliki dua bentuk yaitu mengambil dengan cara yang gelap seperti mencuri, ghasab dan sesamanya, dan mengambil harta dengan jalan yang dilarang seperti perjudian dan sesamanya dari setiap yang diharamkan [14]. 
Allah Swt melarang hamba-Nya untuk memakan harta sebagian dari orang lain, karena hal itu sangat merugikan orang banyak. Selain itu juga termasuk perbuatan yang bathil, yaitu mencuri dan melakukan ghasab, karena hal tersebut berarti memanfaatkan harta orang lain dengan cara yang dilarang oleh agama maupun hukum negara. Sebagaimana dalam tafsir al-Thabari mengatakan bahwa larangan memakan harta sebagian yang lain dengan cara yang bathil, karena hal tersebut tidak dihalalkan oleh Allah Swt [15] Kemudian Allah juga melarang hamba-Nya untuk mengadukan masalah harta itu kepada hakim supaya harta tersebut dapat dimiliki secara penuh lewat jalur hukum padahal hal tersebut telah diketahui oleh dirinya bahwa harta itu bukan haknya.

Penyebab kejahatan koruspi khususnya disebabkan oleh keserakahan dan materialisme, sehingga membutakan orang yang tidak buta matanya. Pesan bijak seorang tokoh sufi dunia, al-Syaikh Ibnu Atha'illah as-Sakandri dalam al-Hikamnya: "Semesta itu seluruhnya gulita. Ia hanya akan diterangi oleh wujud Allah. Siapa yang melihat semesta, tetapi tidak melihat-Nya di sana atau tidak melihat-Nya ketiak, sebelum, atau sesudah melihat semesta, berarti ia telah disilaukan oleh cahaya-cahaya lain dan terhalang dari surya makrifat karena tertutup olrh tebalnya awan dunia”. [16] Yang buta sesungguhnya bukanlah mata fisiknya, melainkan mata hatinya.

Sejalan dengan itu, konsep Alquran tentang perubahan atau perbaikan tidak efektif kecuali perubahan itu dimulai dari dalam sebagaimana diisyaratkan oleh berbagai ayat Alquran

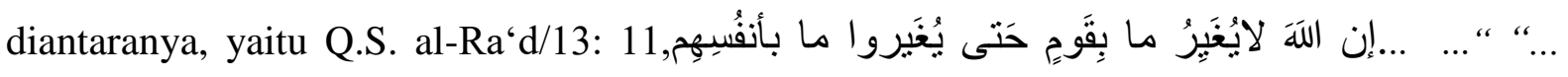
Sesungguhnya Allah tidak merobah keadaan sesuatu kaum sehingga mereka merobah keadaan yang ada pada diri mereka sendiri ...." Ayat ini mengandung informasi yang amat mendasar. Pertama, perubahan bermula dari manusia terlebih dahulu melalui "sisi dalamnya" sebagai makna yang diisyaratkan kata 'anfusihim'. Kedua, perubahan yang bermakna dan efektif harus melalui sekelompok orang, bukan perorangan, sebagaimana diisyaratkan oleh bentuk jamak/plural 'anfusihim' [17] yang digunakan pada ayat di atas. Terma 'anfusihim' (diri mereka sendiri) pada ayat tersebut menunjukkan 'sisi dalam' (inner hidden, soul) manusia yang meliputi idea-idea/nilai-nilai yang terdapat dalam benaknya, serta diyakini kebenaran dan manfaatnya yang melahirkan tekad yang kuat untuk merealisirnya.

Petunjuk ayat di atas antara lain adalah, perubahan harus dilakukan secara simultan, yaitu karakter aparatur dan perbaikan sistem birokrasi. Perbaikan karakter individu dan masyarakat dengan memasukkan nilai-nilai utama yang bersumber dari agama dan budaya harus menyentuh 'sisi dalamnya' yang meliputi mindset, paradigma, persepsi, kesadaran, 
dan ide. Jadi, character building harus mampu menyentuh 'sisi dalam' sebagaimana diisyaratkan dengan kata 'anfus'. Perubahan sistem dan Undang-Undang tidak cukup, karena the man behind the gun. Pendekatan kemanusiaan (human approach) dalam reformasi adalah mutlak bersamaan dengan system approah. Sebab, perubahan perorangan saja tentu tidak efektif sehingga ia harus dilakukan secara kolektif sebagaimana ditunjukan dalam bentuk jamak 'anfus'.

Hal ini sejalan dengan petunjuk surah al-Tahrîm/66: 6, بَا أَيْهَا الذين أمنوا قُو أنفُسَكُم ... "Hai orang-orang yang beriman, peliharalah dirimu dan keluargamu dari api neraka ...”. Perubahan positif akan menjadi efektif apabila didukung dengan keteladanan sebagaimana isyarat kalimat قُقُ ا أَنْسَكُم و أهلِيَمُ pelihara dirimu dan keluargamu. Ayat juga menunjukkan bahwa perubahan harus dimulai dari pejabatnya melalui tatakelola pememrintaha yang bersih. Keteladanan pemimpin dalam mengelola pemerintahan yang bersih akan membawa pengaruh besar terhadap prilaku aparatur negara, termasuk sistem pengawasan yang efektif disertai keteladanan.

\section{Corruption in Local Wisdom Perspective}

Nilai-nilai yang terdapat dalam kebudayaan orang Bugis itu perlu diungkapkan dalam setiap gerak kehidupan orang Bugis dalam menghadapi setiap dinamika kehidupan yang penuh tantangan. Nilai-nilai itu diciptakan karena dimuliakan oleh para leluhur mereka sebagai peletak dasar masyarakat dan kebudayaan Bugis. Selanjutnya, dialihkan dari suatu generasi ke generasi berikutnya. Dalam upaya mewariskannya, ia menyampaikan dalam bentuk nasihat, petuah, pesan - yang dalam lontarak yang disebut pappanngaja dan paseng [18]. Saat ini, kebudayaan Bugis dapat ditelusuri dalam beberapa sumber dan literatur, misalnya dalam "Nilai-Nilai Utama Kebudayaan Bugis" [19]. Kebudayaan orang Bugis mempunyai nilai-nilai utama berupa kejujuran, kecendikiaan, kepatutan, keteguhan, usaha atau kerja keras.

Pertama, Lempu' kejujuran). Lempu' berarti “lurus" yang merupakan antonim dari kata 'bengkok'. Penggunaan kata tersebut dalam berbagai konteksnya, berarti juga ikhlas, benar, baik atau adil. Ini bertentangan dengan sikap curang, culas, dusta, khianat, seleweng, buruk, tipu, dan aniaya. Dalam kaitan ini, syair orang Bugis menyebutkan: "Duwai kuala sappo; unganna panasae, belona kanukue" [20] "Dua (hal) yang kujadikan pagar (pelindung diri dan kehormatan), yaitu bunga nangka dan hiasan kuku". 
Ketika Tociung, Cendikiawan Luwu, diminta nasihatnya oleh calon raja (datu) Soppeng, La Manussa' Toakkareng, menyatakan bahwa diantara inti kejujuran itu adalah tidak serakah dan tidak mengambil yang bukan haknya [21]. Sejalan dengan itu, Kajaolaliddong, cendikiawan Bone, menjelaskan kejujuran "Jangan mengambil tanaman yang bukan tanamanmu, jangan mengambil barang-barang yang bukan barang-barangmu" [22].

Kedua, Amaccang. Dalam bahasa Bugis 'cendikia' sering diartikan 'acca', yaitu pandai atau pintar. To acca adalah orang mempunyai kearifan. Acca adalah prilaku baik cara berpikir maupun cara bertindak dapat menjadi pertimbangan yang arif. Jadi, acca merupakan nilai-nilai kearifan yang menghiasi cara berpikirnya dan bertindaknya. Tidak disebut pula To Acca kalau tidak jujur, serakah, mengambil yang bukan haknya. Ketika orang berilmu serakah, tidak jujur, dan aniaya maka hakikatnya bukanlah ilmuwan.

Ketiga, Asitinajang. Kata ini berasal dari tinaja yang berarti cocok, sesuai, pantas atau patut. Lontarak mengatakan: "Duduki kedudukanmu, tempati tempatmu." [23] Ade' Wari (adat perbedaan) dalam budaya Bugis pada prinsipnya mengatur segala sesuatu agar berada pada tempatnya, termasuk perbuatan mappasitinaja. Hal ini sesuai dengan petuah: "Alai cedde'e risesena engkai mappideceng, sampeangngi maegai risesena engkai makkasolang [24]. Artinya: "Ambillah yang sedikit jika yang sedikit itu mendatangkan kebaikan, dan tolaklah yang banyak apabila yang banyak itu mendatangkan kebinasaan”.

Keempat, Dalam bahasa Bugis keteguhan adalah agettengeng. Prinsip keteguhan orang Bugis tetap pada asas atau setia pada keyakinan, atau kuat dan tangguh dalam pendirian, erat memegang sesuatu. Seperti halnya nilai kejujuran, nilai kecendikiaan, dan nilai kepatutan, [25] nilai agettengeng merupakan martabat orang Bugis. Diantara nilai agettengeng yaitu tidak mengingkari janji, kedua, tidak menghianati kesepakatan, tidak membatalkan keputusan secara sepihak. Semua pejabat berjanji dan disumpah tidak akan menyalah gunakan wewenang dan akan setiap kepada janji, termasuk tidak korupsi.

Kelima, reso. Reso adalah budaya kerja atau etos kerja yang sangat erat kaitannya dengan nilai-nilai kejujuran (lempu'), kecendikiaan (amaaccang), kepatutan (asitinajang), dan keteguhan (agettengeng). Bahkan, usaha dan kerja keras (reso) adalah kunci bagi pelaksanaan nilai-nilai lempu', acca, asitinajang, getteng, sebab nilai-nilai ini baru dapat berperan secara tepat guna dan berdaya guna apabila didukung oleh nilai-nilai usaha (reso). Dengan sendirinya, nilai usaha ini pun tegak di atas landasan nilai-nilai tersebut [26]. Kerja 
nyata merupakan yang dibingkai dengan nilai-nilai tersebut akan mengantar pada hasil kerja yang maksimal yang melahirkan kepercayaan publik (public trust). Reso merupakan prinsip orang Bugis yang bertentangan dengan sifat malas, mengambil dan menerima yang bukan hasil kerjanya.

Keenam, Siri'. Siri' pada mulanya mengandung makna yang berkonotasi posistif, tetapi dapat pula berkonotasi negatif [27]. Siri' seringkali dimaknai sebagai nilai bagi orang Bugis. Karena itu, jika seseorang melakukan hal-hal yang tidak baik, itu memalukan (mappakasisri'). Jika ia melakukan hal-hal yang jelek dan memalukan di saat itulah harga diri dan nilainya turun. Sebaliknya, jika ia melakukan hal positif dan baik, di saat itulah ia menaikkan derajat kemanusiaannya sebagai orang Bugis.

Orang yang telanjang dari perasaan malu (siri') adalah telanjang dari aspek moralitas, dan oleh lontara' orang itu diserupakan dengan binatang. Binatang paling buruk adalah binatang yang kerjanya hanya melakukan kerusakan, menjengkelkan, menjijikkan, yakni tikus. Di sawah ia merusak tanaman (hama), setelah dipanen dan disimpan di rakkiang rumah juga dirusak, selesai ditumbuk menjadi beras, sudah dimasak, tikus terus mempreteli. Nasi yang sudah dimakannya, dikencingi, diberaki pula, kemudian ia turun ke tanah dan di situ tahi pun dijilatnya, dinding dilobangi, dan kejahatan lainnya.

Koruptor sering disimbolkan dengan tikus. Jika melakukan perbuatan yang menyerupai sifat tikus, kerjanya merusak sistem, melanggar aturan, mengacaukan kehidupan, mengumbar aib diri dan orang lain di saat itulah manusia jatuh harga diri dan wibawanya. Nilai siri' yang berkonotasi positif harus ditegakkan, sehingga tatanan kehidupan masyarakat menjadi lebih bermartabat dan memberikan nilai-nilai positif bagi kehidupan. Siri' adalah harga diri, martabat, khususnya bagi masyarakat Bugis, yang dalam konteks Islam bahkan, siri' itu adalah bagian dari iman. Artikel ini menegaskan bahwa adat yang dipegang dengan teguh, bersanding dengan kepatuhan terhadap agama [28], [29].

\section{CONCLUSION}

Korupsi merupakan sebuah kejahatan yang bertentangan dengan nilai-nilai yang dianut. Penyebab korupsi adalah dominasi syahwat materialisme, yang melahirkan sifat-sifat curang, culas, dusta, khianat, seleweng, buruk, tipu, dan aniaya. Sifat-sifat ini apabila dipaket dengan serakah dan materialistik maka akan mendorong dengan kuat manusia melakukan korupsi. Kejahatan korupsi muncul sebagai akibat dari materialisme yang berlebihan. Korupsi 
berawal dari kejahatan batin melahirkan sifat buruk dan terakumulasi menjadi malapetaka. Korupsi tidak hanya berdampak buruk bagi kehidupan ekonomi, sosial, politik, dan hukum. Secara teologis, pelakunya akan dimasukkan kedalam neraka kecuali mereka yang bertobat dan diterima tobatnya. Alquran memberikan tuntunan bahwa kejahatan korupsi harus dicegah dan diatasi dengan melakukan perubahan paradigma, pemikiran, dan mindset. Perubahan yang efektif harus berjalan secara simultan baik secara struktural maupun secara kultural. Kearifan lokal mesti ditegakkan sejalan dengan nilai-nilai agama. Nilai-nilai kearifan lokal berupa lempu' (al-shidq), amaccang (al- 'ma 'rifat), agettengeng (istiqamah), asitinajang (al'adl), reso (al-'amal), and siri' (al-haya') sesungguhnya ditemukan dalam Alquran. Nilainilai kearifan lokal tersebut dikenal dalam ushul fiqh dengan istilah al- 'urf.

\section{IMPLIKASI}

Konsep Alquran sejalan dengan nilai-nilai kearifan lokal masyarakat Bugis. Alquran menyebut 'sisi dalam' nilai-nilai lempu', amaccang, agettengeng, asitinajang, reso, and siri' hanya bisa berjalan efektif jika dilandasi oleh sebuah kesadaran yang tumbuh dari kedalaman batin dan kebeningan jiwa. Jika Alquran menekankan pada kolektifitas dalam melakukan perbaikan maka kebudayaan Bugis memberi petunjuk bahwa nilai-nilai kearifan lokal akan bertumbuh subur apabila sejalan dengan nilai-nilai religius. Konsep pengawasan diri membutuhkan sebuah pembinaan yang menyentuh 'sisi dalam' berupa kesadaran yang mendalam yang memperbaiki cara pandang dan meluruskan niat. Hal ini sejalan dengan pandangan Quraish Shihab yang memaknai kata 'anfus' sebagai ‘sisi dalam’ pada manusia.

Sejalan dengan itu, konsep percaya pada hari akhirat antara lain dapat menuntun manusia untuk tidak melakukan kejahatan korupsi, sebab pengadilan tidak berakhir di dunia, melainkan justru pengadilan yang seadil-adilnya adalah pengadilan Allah di akhirat kelak. Pengawasan dengan pendekatan agama merupakan sebuah langkah yang tepat dan efektif apabila dijalankan secara konsisten dan berkelanjutan. Pengawasan diri (self control) yang didukung sebuah sistem pengawsan dan pengendalian yang baik akan mempercepat penanganan kasus korupsi. Langkah-langkah pencegahan harus diprioritaskan disamping mempercepat penyelesaian berbagai kasus korupsi yang ada. Disamping itu, masyarakat khususnya para penguasa harus didekatkan kepada nilai-nilai kearifan lokal asal mereka dan serta memperkuat muatan lokal di lemabag pendidikan untuk mengimbangi tantangan budaya global yang semakin deras dan kuat pengaruhnya sebagai pandangan A. Faisal Bakti. 


\section{REFERENSI}

[1] Andi Faisal Bakti, "Kita Harus Menghormati Local Value", Khazanah Islam Nusantara: Rekam Jejak Dialektika Islam dan Local Value. Jurnal Bimas Islam , Vol. 2, No. 1, (Jakarta: Bimas Islam Depag RI, 2009), h. 30.

[2] Ismail Suardi Wekke, dan Yuliana Ratna Sari. "Tifa Syawat dan Entitas Dakwah dalam Budaya Islam: Studi Suku Kokoda Sorong Papua Barat." THAQAFIYYAT: Jurnal Bahasa, Peradaban dan Informasi Islam 13.1 (2014): 163-186.

[3] Ismail Suardi Wekke, dan Maimun Aqsha Lubis. "A Multicultural approach in Arabic language teaching: creating equality at Indonesian pesantren classroom life." Sosiohumanika 1.2 (2016).

[4] Tim Penyusun, Mengembangkan Budaya Kerja Melalui Pengawasan dengan Pendekatan Agama (Cet. V; Jakarta: Itjen Kementerian Agama RI., 2011), h. 3-4.

[5] Sayyid Agil dan Masykut Hakim, h. 4.

[6] Badr al-Din al-Zarkasyi, al-Burhan fi 'Ulum al-Qur'an, Jilid 1 (Cet. I; Kairo: al-Halabi, 1975), h. 36.

[7] al-Zarqaniy, Manahil al-'Irfan fiy 'Ulum al-Qur' an (Bairut: Dar al-Fikr, 1988), h. 184.

[8] Dimas Rachman Taufiq di http://sevation07.blogspot.com/2013/11/korupsi-kolusi-dannepotisme-dalam.html, diunduh tanggal 08/12/2016.

[9] Buya Hamka, Tafsir Al-Azhar Juz II (PT Pustaka Panjimas, Jakarta, 1984), h. 110.

[10] Hasan Alwi, Kamus Besar Bahasa Indonesia, (Jakarta, Balai Pustaka, Edisi 3, 2005), 594.

[11] Ismail Suardi Wekke. "Tradisi Pesantren dalam Konstruksi Kurikulum Bahasa Arab di Lembaga Pendidikan Minoritas Muslim Papua Barat." KARSA: Jurnal Sosial dan Budaya Keislaman 22.1 (2015): 20-38.

[12] Ahmad Musatafa Al-Maraghi, Tafsir Al-Maraghi (Semarang: Toha Putra, 1984) cet ke1 hal: 150

[13] Syekh Muhammad showi al-maliki, hasyiatusshowi, jilid satu hal: 86-87

[14] Wahbah Zuhailiy, Tafsir al-Munir fi al-aqidati wa wa al-syariati wa al-manhaj, surat al-Baqarah ayat 188 (Damsyq: Dar al-Fikr), al-mujallid awwal, hal. 529.

[15] Software al-Maktabah Syamilah, Tafsir al-Thabari. surat al-Baqarah ayat 188, juz 3, hal. 549.

[16] Al-Syaik Abdullah, Asy-Syarqawi, Syarh al-Hikam Ibnu Atha'illah as-Sakandari. Terj. Imam Fidaus, Cet. I; Jakarta Selatan Wali Pustaka, 2016.

[17] M. Quraish Shihab, "Pendidikan Nilai untuk Pembentukan Sikap dan Prilaku", dalam Jurnal Pendidikan, Pendidikan Islam dan Tantangan Modernitas (Ujung Pandang: Lentera Fak. Tarbiyah IAIN Alauddin 1997).

[18] A. Rahman Rahim, Nilai-Nilai Utama Kebudayaan Bugis (Yogyakarta: Ombak, 2011), Dikutip dari Prof. Drs. G.H.M. Riekerk "Lahirnya Kedatuan Tomanurung" (ceramah), Fakultas Hukum Universitas Hasanuddin Ujung Pandang, 13 Agustus 1969.

[19] A. Rahman Rahim, Nilai-Nilai Utama ..., h. 37-66.

[20] Mursalim, "Tafsir Bahasa Bugis/Tafsir al-Qur'an al-Karim Karya Majelis Ulama Indonesia (MUI) Sulawesi Selatan; Kajian terhadap Pemikiran-Pemikirannya" Disertasi (Jakarta: UIN Syarif Hidayatullah, 2008), h. 231-232.

[21] A. Rahman Rahim, Nilai-Nilai Utama Kebudayaan Bugis..., h. 119-120.

[22] A. Rahman Rahim, Nilai-Nilai Utama...., h. 235. 
[23] A. Rahman Rahim, Nilai-Nilai Utama....., h. 126.

[24] A. Rahman Rahim, Nilai-Nilai Utama ....., h. 126.

[25] A. Rahman Rahim, Nilai-Nilai Utama ....., h. 130. Dikutip dari A. Hasan Machmud, h. 76 butir 108 .

[26] A. Rahman Rahim, Nilai-Nilai Utama...., h. 133.

[27] A. Rahman Rahim, Nilai-Nilai Utama....., h. 136-140.

[28] Ismail Suardi Wekke. "Islam dan Adat dalam Pernikahan Masyarakat Bugis di Papua Barat." THAQAFIYYAT: Jurnal Bahasa, Peradaban dan Informasi Islam 13.2 (2014).

[29] Ismail Suardi Wekke. "Islam dan adat: tinjauan akulturasi budaya dan agama dalam masyarakat Bugis." Analisis: Jurnal Studi Keislaman 13.1 (2017): 27-56. 